\title{
Accommodation fatigue and dark focus: The effects of accommodation-free visual work as assessed by two psychophysical methods
}

\author{
R. J. MILLER, RICHARD G. PIGION, MICHAEL F. WESNER, \\ and JAMES G. PATTERSON \\ Washington State University, Pullman, Washington
}

\begin{abstract}
Past studies of accommodation fatigue have yielded inconsistent results, partly because they have not used direct measures of accommodation, and partly because they may have been based on a misleading conception of the nature of accommodation. The dual-innervation theory of accommodation suggests that the resting position of accommodation may be neuromuscular rather than just muscular, and that it lies not at optical infinity, as assumed by older conceptions, but at some intermediate position (dark focus). Among the predictions that may be deduced from this theory is that long-term visual work not requiring active accommodation will not induce fatigue. The present study involved continuous measurements of dark focus for 10 young adults over a 3-h period, using the laser optometer with two psychophysical procedures (bracketing and staircase). Consistent with the prediction, no changes in dark focus were found, in spite of the demanding visual task. Furthermore, it was found that both psychophysical methods yielded essentially identical results. The practical and theoretical implications of these results are discussed, and recommendations are given regarding situations in which each of the psychophysical methods is likely to be most useful.
\end{abstract}

As far back as 1864, Donders (Berens \& Stark, 1932) suggested that eyestrain (asthenopia) resulted from excessive near work, producing fatigue of the muscular system for accommodation. Those who have accepted that explanation (e.g., Fitzpatrick \& Hansen, 1973; Romaine, 1951; Simmerman, 1950; Weston, 1954) generally have assumed that the physiological effort required for close visual work leads to a temporary decrease in the ability of the ciliary muscle to contract, with an accompanying decrease in amplitude of accommodation, manifested by a recession of the near point. Several studies, some of them very old, frequently are cited as evidence that close work leads to such near-point recession (e.g., Berens \& Sells, 1944; Berger \& Mahneke, 1954; Ferree, 1913, 1914; Fitzpatrick \& Hansen, 1973; Howe, 1916). Others have presented contrary evidence (e.g., Berens \& Sells, 1950; Berens \& Stark, 1932; Heaton, 1966; Lancaster \& Williams, 1914).

Unfortunately, none of these studies used direct measurements of either the physiological or refractive power changes involved in accommodation,

Portions of this study were presented at the annual meeting of the Western Psychological Association, San Francisco, April 1983. This research was supported in part by funds provided by the State of Washington Initiative Measure No. 171 for medical and biological research on alcoholism. Requests for reprints should be addressed to R. J. Miller, 209 Johnson Tower, Department of Psychology, Washington State University, Pullman, Washington 99164. most relying on inferences drawn from acuity or blur. Östberg and his colleagues (Östberg, 1980; Östberg, Powell, \& Blomkvist, Note 1), however, have reported studies in which more direct measures of the eye's refractive state were made using laser optometry. They were particularly interested in the effects of long periods of watching visual display units (VDUs), and reported that several hours of VDU work tended to produce two results. One was an increase in the degree to which subjects overaccommodated for far targets and underaccommodated for near targets, implying that fatigue not only changes the near point, but also induces a degree of myopia for far targets. The other reported effect was an increase in dark focus accommodation.

\section{Dark Focus and the Dual-Innervation Theory}

Dark focus is the degree of accommodation in force in the absence of an effective accommodative stimulus (Leibowitz \& Owens, 1975, 1978). It generally refers to the refractive aspects of accommodation, in that dark focus is expressed as the dioptric value by which the refractive power of the eye in total darkness exceeds that eye's minimal refractive state. There are relatively wide interindividual differences in dark focus; its values among young adults range from 0 to about 4 diopters (D), with a mean in the neighborhood of 1.70 to $2.75 \mathrm{D}$ (Leibowitz \& Owens, 1975; Miller, 1978a). Dark focus also frequently is specified in terms of the distance between the ideal eye and the location a target would have to assume to 
be in retinal focus when the eye is at dark focus. This location is referred to as the dark focus point.

The traditional conception of accommodation, dating back at least to Helmholtz (e.g., Alpern, 1969; Brown, 1965; Duke-Elder \& Abrams, 1970; Leibowitz \& Owens, 1978) is that the "resting" position of accommodation corresponds to the physiological and refractive state of the eye when it is focused on its far point (infinity in the ideal eye), that is, when the eye has assumed its minimal refractive state. This conception assumes that accommodative increases in the eye's refractive power are due to parasympathetically innervated changes in the ciliary muscle. Fatigue effects lead to recession of the near point in the direction of this resting point. Only near work can cause fatigue, since for far work (except, perhaps, in the case of hypermetropes) the accommodation system is viewed as being completely relaxed. Fatigue effects are thought to be muscular, produced by overworking the ciliary muscle. Relaxed muscles do not, by most definitions, fatigue.

However, the dual-innervation theory of accommodation presents a somewhat different definition of "resting" state, suggesting that it be defined not in solely muscular terms, but in neuromuscular ones. Such a resting state represents a tonic state, a balance between sympathetic and parasympathetic forces in the ciliary muscle (Cogan, 1937; Davson, 1980; Leibowitz, 1976; Leibowitz \& Owens, 1978; Melton, Purnell, \& Brecher, 1955; Miller \& LeBeau, 1982; Schober, 1954; Toates, 1970, 1972). It is this tonic state that the eye assumes in the absence of a visual stimulus for accommodation, the refractive value of which is defined by dark focus. Relative to this tonic refractive state, increases in parasympathetic innervation induce increases in refractive power, and increases in sympathetic activity lead to decreases in refractive power. Both types of change are viewed as active processes. Applying this conception, fatigue effects may be seen as decreasing the amplitude of accommodation in either direction around this tonic position.

Several predictions may be deduced from this conception. One is that fatigue is characterized not only by a recession of near accommodation, as suggested in early studies, but also by a progression of far accommodation. That is, both extremes move toward dark focus. This is precisely what Ötberg and his associates showed. Another prediction is that one should be able to produce fatigue not only with near work, but with far work as well. Both of these predictions depend, of course, on the actual location of the dark-focus point for a given observer (Östberg et al., Note 1). For subjects with far dark-focus points, very little additional accommodative change is required for clear resolution of far targets, but considerable additional accommodation is required for near targets. Such subjects might be expected to show strong fatigue effects from near work, but few, if any, such effects for far work. On the other hand, subjects with close dark-focus points require considerable accommodative change to focus far targets, but relatively little additional accommodation for near targets. Such subjects might be expected to show strong fatigue effects for far work, but little, if any, fatigue for near work.

Another prediction, and the one that is central to the present study, is that visual work that does not involve accommodative effort should produce no fatigue effects. That is, if dark focus is a true physiological resting state, and the visual task requires no accommodative change either in front of or beyond the dark-focus point, there is theoretically no active accommodation taking place in either direction and nothing that could produce fatigue. Such visual work should produce no change in accommodation amplitude, and certainly should not produce any change in the position of the dark-focus point itself.

Available data indicate that the dark-focus point is quite resistant to change (Miller, 1978b), although certain conditions, particularly certain types of emotional stress, can produce significant increases (Leibowitz, 1976; Miller, 1978b; Miller \& LeBeau, 1982). As previously mentioned, Östberg and his associates also have shown that prolonged viewing of VDUs can produce significant increases in dark focus. This suggests that not only does accommodation amplitude decrease after close-accommodation visual work, but also that there are fatigue effects on dark focus itself. As stated above, however, if visual work requires no accommodation change in front of or beyond the dark-focus point, there should be no change in the dark-focus point as a result of such work. One of the principle purposes of the present study was to test this prediction.

Any visual task designed to test fatigue effects in the absence of active accommodation must be one that allows accommodation to remain at dark focus. One way to do this would be to determine each subject's dark-focus point, and place any visual targets at that distance. The problem with this approach would be that if dark-focus shifts did occur during the fatigue period, one would have to keep moving the target to coincide with the changing dark-focus point. Another way is to give the subject no accommodative target at all-to keep him/her in total darkness. If one takes continuous measures of dark focus using a laser optometer, the measurements themselves constitute a tedious visual task. They do not, however, require active accommodation. To understand this point, it is necessary to review the operation of the laser optometer.

\section{The Laser Optometer}

Various stages and refinements in the development of the laser optometer have been reported (Hennessy 
\& Leibowitz, 1970, 1972; Ingelstam \& Ragnarsson, 1972; Knoll, 1966; Leibowitz \& Hennessy, 1975; Mohon \& Rodemann, 1973). The version that has been used by the present senior author in past studies (e.g., Miller, 1978a, 1978b, 1980; Miller \& LeBeau, 1982) is shown in Figure 1. A beam of light from a low-power laser is diverged and reflected from the surface of a slowly revolving drum. The reflected laser pattern is superimposed in the subject's left-eye visual field. This pattern is perceived by the subject as a display of dark speckles on a round red field.

The speckles in the pattern are usually perceived as moving, the direction of this movement being determined by the direction of movement of the drum and the eye's refractive state. If the eye is accommodated to a point closer than the optical distance of the drum, the speckles are perceived as moving in the same direction as the drum's rotation. If the subject is accommodated beyond the optical distance of the drum, the opposite movement is perceived. The speckle pattern itself has no effect on accommodation (Hennessy \& Leibowitz, 1970; Leibowitz \& Owens, 1975).

A Badal lens (typically 4 or $5 \mathrm{D}$ ) is inserted into the path of the laser pattern, between the observer and the drum, at a distance of one focal length from the subject's eye. The optical distance of the drum can be varied from infinity to $20-25 \mathrm{~cm}$ (depending on the power of the Badal lens), without changing the apparent size or brightness of the speckle pattern (the Badal principle-see Hennessy \& Leibowitz, 1972; Ogle, 1968), although the actual distance of the drum from the eye varies only over a range corresponding to the focal length of the Badal lens.

For taking accommodation measurements, a "bracketing" technique is typically used. The speckle pattern is flashed for $0.5 \mathrm{sec}$ at irregular intervals. After each exposure, the observer indicates the perceived direction of movement of the pattern (up or down). At the beginning of each series of trials, the drum is located at extreme near and far optical distances (thus "bracketing" the accommodation point). With succeeding presentations, the distance



Figure 1. The laser optometer. between near and far flashes gradually is reduced until the point of no apparent motion is found. This value is recorded as the accommodation point, with corrections added for chromatic aberration (Owens \& Leibowitz, 1975) and for the fact that the effective plane of stationarity is actually somewhat behind the drum's surface (Charman, 1974).

\section{Purposes of the Present Study}

The strategy of the present study was to take continuous assessments of accommodation in total darkness for $3 \mathrm{~h}$. There were three purposes for doing this:

(1) As can be imagined, this is a demanding visual task. It requires that the subject remain in a fixed position for a 3-h period, constantly alert to movement in the speckle pattern. However, it makes no demands on accommodation-since there is no accommodative target, accommodation remains at dark focus. According to the dual-innervation theory, such a task should result in no change in the dark-focus point, since accommodation itself is not being fatigued. One purpose of the present study was to test this prediction.

(2) The second purpose was a practical one. It frequently is necessary in accommodation studies to perform lengthy manipulations. It would be useful to know if dark-focus changes over long experiments are due just to the influence of the independent variables or if fatigue effects must also be taken into account. Östberg and his associates, as described above, did show some changes in dark focus following $2 \mathrm{~h}$ or more of VDU work. It would be useful to have baseline data regarding the effects of long-term viewing on dark focus in a "pure" visual context, in which there are no stimulus demands on accommodation.

(3) A third purpose was to examine the differential utility of two psychophysical procedures. As described above, the usual procedure is to use a bracketing technique. This is relatively efficient, but it is not, strictly speaking, very good psychophysics, because it yields only one transition point for each bracketing series. The use of several series of bracketing trials, or of a conventional method of limits approach utilizing several ascending and descending series, would be better psychophysics, since each series would produce a transition point. However, the use of numerous series of trials for each measurement would be too time-consuming for many applications.

There is, however, a variation of the method of limits that is more efficient than the use of numerous ascending and descending series. This is called the staircase, or up-and-down, method (Cornsweet, 1962; Dixon \& Massey, 1957; Guilford, 1954). A quotation from Dember and Warm (1979) will convey the principal idea: 
To measure the [threshold] with this method, the investigator begins as in the usual method of limits, but changes direction after each change in the observer's response. If the observer responds "Yes" to a stimulus, the next stimulus is made weaker; if the response is "No," the next stimulus is made stronger. The stimulus is increased or decreased in constant steps from trial to trial, and the procedure is continued until a predetermined number of trials is reached. (p. 37)

The principal advantage of the staircase method is that it gives a number of transition points, but requires far fewer trials than the conventional method of limits.

The present study used both the bracketing method and the staircase method to obtain measurements of dark focus. This made it possible to compare the two methods in terms of accommodation values yielded, variability, and the time required to make measurements.

\section{METHOD}

\section{Subjects}

There were 10 subjects ( 5 males and 5 females), 22-28 years old. The mean age for each sex was 24.2 years. No subject had corrected left-eye acuity of less than $20 / 25$ far or $13 / 16$ near, or significant phorias. Those who normally wore contact lenses did so throughout the study. ${ }^{1}$ No subject was used who normally wore glasses, since the presence of the frames would have interfered with the equipment. No subject was used who had a history of strabismus or other visual anomalies.

\begin{abstract}
Apparatus
The optometer shown in Figure 1 and described earlier was used to make all dark-focus assessments. The Badal lens was an ophthalmic lens with a back vertex power of $4 \mathrm{D}$. The anterior plane of the subject's iris was located $25 \mathrm{~cm}$ from the nearest surface of the Badal lens. With this particular apparatus, the corrections for chromatic aberration and for the drum's effective plane of stationarity exactly cancelled each other.

The subject, secured in position by a chinrest, viewed the speckle pattern through an American Optical phoroptor. While the phoroptor was not necessary for the present study (no lenses or prisms were used), it provided a convenient way of maintaining correct distance between the subject's eye and the Badal lens.
\end{abstract}

\section{Procedure}

The subject sat in an adjustable optometric chair. The phoroptor was adjusted for the subject's interpupillary distance, and the chair and chinrest were adjusted to assure correct viewing distance and maximum comfort. The study took place in total darkness, the only light available to the subject being the periodic exposures of the speckle pattern. The task was briefly explained to the subject and a few minutes of practice were given until it was clear that he/she perceived the movement of the speckle pattern reliably. Following practice, $3 \mathrm{~h}$ of continuous dark-focus measurements were made. Two psychophysical techniques were used, a bracketing technique and a staircase technique.

Bracketing technique. The bracketing technique was used as partially described earlier. The optical bench along which the drum moved was marked off in $1-\mathrm{cm}$ units, representing points from 0 to $25 \mathrm{~cm}$ from the Badal lens. Each series of trials began with the drum at either the extreme far or extreme near end of the scale, and involved alternating the drum's position randomly from one extreme to the other. Each trial for a given extreme involved a setting $1 \mathrm{~cm}$ closer to the center than had the previous trial at that ex- treme. At each setting, the speckle pattern was exposed to the subject for $0.5 \mathrm{sec}$, and he/she indicated the direction of speckle movement. In this manner, it was possible to localize the shift from perceived upward to perceived downward movement. In practice, once a subject's approximate dark focus was known, it was possible to streamline the procedure by eliminating trials for positions that were far away from the dark-focus point.

Thus, each series of trials provided one transition point. Each bracketing measurement consisted of three series of trials, given consecutively. The dark-focus value could be represented in two ways. Some studies (e.g., Miller, 1978a, 1978b) have used the mean of the three series' transition values as the accommodation value. This was one method of recording dark focus in the present study and will be labeled 3-series bracketing. Other studies (e.g., Miller \& LeBeau, 1982) have used just one series of trials and have treated the resulting single estimate as the accommodation value. This approach is obviously quicker than using three series, but one wonders if it produces reliable values, particularly when the interest is in individual subject responses rather than group data. The present study also used this method by recording the threshold value obtained in the first of each of the three series of trials. This method will be labeled 1 -series bracketing.

Staircase technique. For the staircase method, each measurement began with the drum in a position that the experimenter knew from brief pretesting to be near the subject's dark-focus point. If the subject responded "up" as his/her perception of the direction of movement, the experimenter knew that the dark-focus point was between the drum and the Badal lens, and moved the drum $1 \mathrm{~cm}$ closer to the lens and presented another trial. If the subject now said "down," the experimenter knew that the dark-focus point had been crossed. For the next trial, he moved the drum $1 \mathrm{~cm}$ further away from the Badal lens. The experimenter kept changing the drum's position, $1 \mathrm{~cm}$ at a trial, in the same direction until the subject's response changed. With each change in response, the experimenter changed the direction in which he shifted the drum for the next trial. A complete measurement consisted of 30 trials. Each shift in the subject's response represented a transition point. The mean of all the transition points for a set of $\mathbf{3 0}$ trials represented one dark-focus measurement.

Throughout the $3 \mathrm{~h}$ of measurements, the two methods (staircase and bracketing) were alternated on an ABBA pattern. The method with which each session began was counterbalanced across subjects. A record was kept of the time (to the nearest minute) required for each measurement. After the 3-h session was completed, the subject was debriefed and dismissed.

\section{RESULTS}

Variations in dark focus across the $3 \mathrm{~h}$ of measurements are shown in Figures 2 and 3. These graphs combine the dark-focus values obtained for both staircase and 3-series bracketing methods. As will be shown below, there were no significant sex differences in dark focus. The results are separated by sex in these two figures only as a convenience to avoid the confusion that would result from placing all 10 curves on one graph.

\section{Comparison of Psychophysical Methods}

One of the principal questions was whether the psychophysical methods yielded different dark-focus values. To evaluate this effect, a $2 \times 3 \times 3$ (sex $\times$ method $\times$ time) analysis of variance was performed, with dark focus as the dependent variable. Sex of subject was incorporated as an independent variable in most of the analyses used for this study. Since 


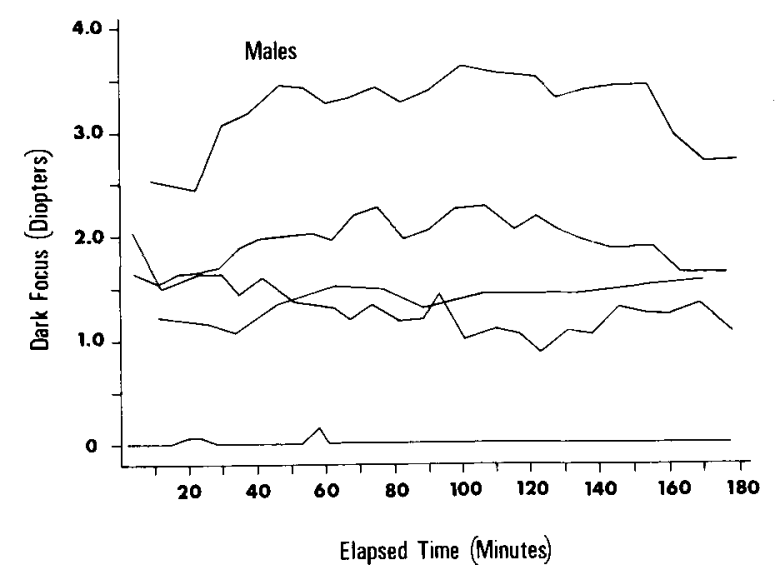

Figure 2. Variation in dark focus for male subjects across the 3 h of measurement.

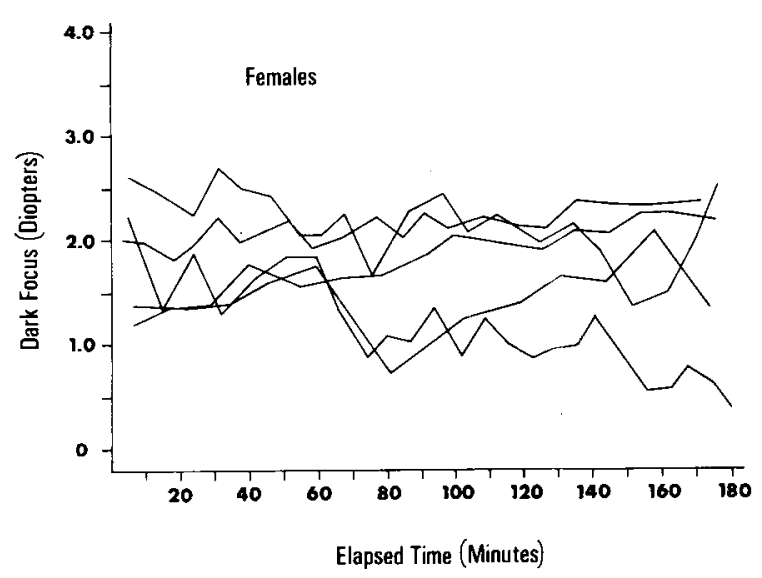

Figure 3. Variation in dark focus for female subjects across the $3 \mathrm{~h}$ of measurement.

there were only five subjects of each sex, however, any effects of this variable should be interpreted cautiously. The three levels of the method variable were staircase, 3-series bracketing, and 1-series bracketing. The three levels of the time variable represent the $3 \mathrm{~h}$ of measurement. For each subject, the mean of the dark-focus values for each method was calculated for the first hour, for the second hour, and for the third. The dark-focus values obtained for each of the resulting cells are shown in Table 1 . There were no statistically significant main effects for any of the three independent variables and no significant interactions.

For each subject, the mean of all his/her darkfocus values obtained by the staircase method was computed. The same was done for the 1-series bracketing and 3-series bracketing procedures. This yielded three mean values for each subject, one for each of the three methods. Across all 10 subjects, the Pearson product-moment correlation coefficients were calculated for each of the three pairs of methods, using these mean values. The staircase and 1 -series bracketing methods correlated $r=0.988$, the 1-series bracketing and 3-series bracketing methods correlated $r=0.998$, and the staircase and 3-series bracketing techniques correlated $r=0.992$. The scatter diagram for this last correlation is shown in Figure 4.

\section{Variability of Staircase Method}

The 30 trials of each staircase measurement provided two ways in which variability could be assessed. One way was to find the standard deviation of all the transition points represented in these $\mathbf{3 0}$ trials. The other was to count the number of transition points (a decrease in this number indicated an increase in variability). Two $2 \times 3$ (sex $\times$ time) analyses of variance were conducted, one with standard deviation as the dependent variable and the other with the number of transitions as the dependent variable. The three levels of the time variable represented the $3 \mathrm{~h}$ of measurement. For each subject, the mean standard deviation or mean number of transitions for all the staircase measurements within a given time period was calculated. The cell means and the standard deviations are shown in Table 2.

The analysis of variance for the standard deviation values showed no significant main effects or interaction, although the sex difference was nearly significant $[F(1,8)=3.96, p=.08]$. That is, there was some tendency for females to be more variable than males. The analysis of variance for the number of thresholds showed a significant effect of time $[F(2,16)=10.49, p=.001]$. That is, the number of thresholds per measurement significantly decreased (i.e., variability increased) as a function of time. Both sexes decreased in number of thresholds per measurement from the first hour to the second. However, from the second hour to the third, the females

Table 1

Dark Focus Data as a Function of Sex, Method, and Time

\begin{tabular}{|c|c|c|c|c|c|c|}
\hline \multirow[b]{3}{*}{ Sex } & \multicolumn{6}{|c|}{ Time of Measurement } \\
\hline & \multicolumn{2}{|c|}{ First Hour } & \multicolumn{2}{|c|}{ Second Hour } & \multicolumn{2}{|c|}{ Third Hour } \\
\hline & $\mathbf{M}$ & SD & $\mathbf{M}$ & SD & M & SD \\
\hline \multicolumn{7}{|c|}{ Staircase } \\
\hline $\begin{array}{l}\text { Males } \\
\text { Females }\end{array}$ & $\begin{array}{l}1.53 \\
1.80\end{array}$ & $\begin{array}{r}1.09 \\
.50\end{array}$ & $\begin{array}{l}1.65 \\
1.64\end{array}$ & $\begin{array}{r}1.28 \\
.57\end{array}$ & $\begin{array}{l}1.49 \\
1.83\end{array}$ & $\begin{array}{r}1.10 \\
.65\end{array}$ \\
\hline \multicolumn{7}{|c|}{ 3-Series Bracketing } \\
\hline $\begin{array}{l}\text { Males } \\
\text { Females }\end{array}$ & $\begin{array}{l}1.52 \\
1.83\end{array}$ & $\begin{array}{r}1.07 \\
.34\end{array}$ & $\begin{array}{l}1.61 \\
1.72\end{array}$ & $\begin{array}{r}1.22 \\
.46\end{array}$ & $\begin{array}{l}1.58 \\
1.67\end{array}$ & $\begin{array}{r}1.21 \\
.55\end{array}$ \\
\hline \multicolumn{7}{|c|}{ 1-Series Bracketing } \\
\hline $\begin{array}{l}\text { Males } \\
\text { Females }\end{array}$ & $\begin{array}{l}1.60 \\
1.83\end{array}$ & $\begin{array}{r}1.11 \\
.40\end{array}$ & $\begin{array}{l}1.60 \\
1.69\end{array}$ & $\begin{array}{r}1.26 \\
.44\end{array}$ & $\begin{array}{l}1.57 \\
1.61\end{array}$ & $\begin{array}{r}1.24 \\
.53\end{array}$ \\
\hline
\end{tabular}

Note-All means are expressed in diopters of accommodation. 


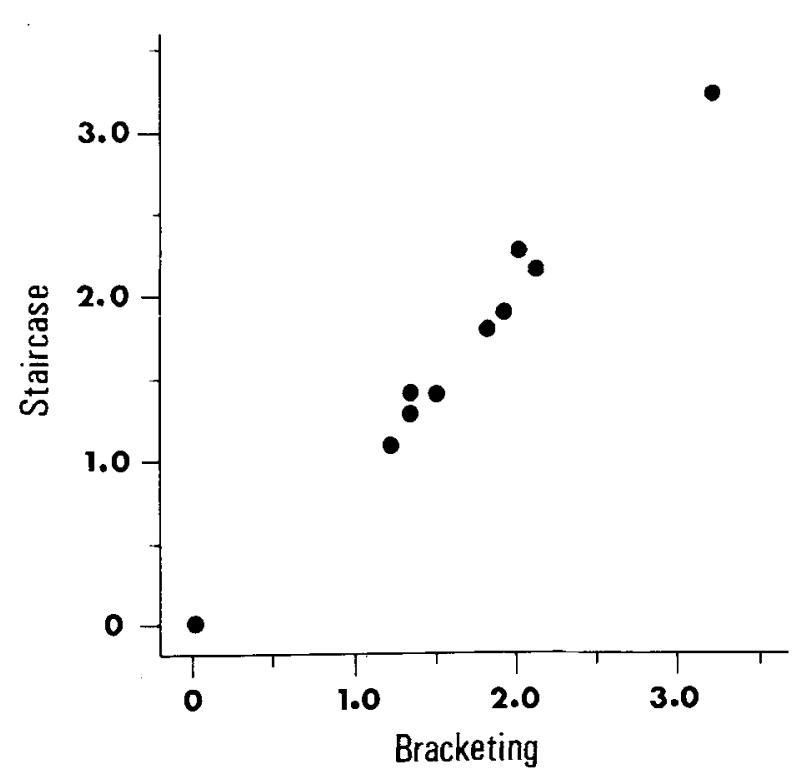

Figure 4. Scatter diagram comparing the mean dark-focus values (expressed in diopters) for all 10 subjects obtained by the 3series bracketing and 30-trial staircase procedures.

increased again, while the males continued to decrease. This interaction between time and sex was nearly significant $[F(2,16)=3.01, p=.08]$, although the reliability of this "near significance" is questionable because of heterogeneity of variance.

\section{Variability of Bracketing Method}

As with most psychophysical procedures, it is not uncommon for a series of bracketing trials to show several transition points. The uncertainty range is defined as the range of those transition points, with the midpoint of the range treated as the criterion variable. Variability of response can be assessed by measuring the range of uncertainty for each series of trials. Thus, it is possible to have a variability measure for the 1-series bracketing method (the range of uncertainty for the first series of the three in each assessment) and for the 3-series bracketing method (the

Table 2

Variability Data for Staircase Method

\begin{tabular}{|c|c|c|c|c|c|c|}
\hline \multirow[b]{3}{*}{ Sex } & \multicolumn{6}{|c|}{ Time of Measurement } \\
\hline & \multicolumn{2}{|c|}{ First Hour } & \multicolumn{2}{|c|}{ Second Hour } & \multicolumn{2}{|c|}{ Third Hour } \\
\hline & $\mathbf{M}$ & SD & $\mathbf{M}$ & SD & $\mathbf{M}$ & SD \\
\hline \multicolumn{7}{|c|}{$\mathrm{SD}_{\mathrm{L}}^{*}$} \\
\hline Males & .14 & .08 & .13 & .07 & .16 & .09 \\
\hline Females & .21 & .04 & .23 & .04 & .23 & .06 \\
\hline \multicolumn{7}{|c|}{ Numbers of Transitions** } \\
\hline $\begin{array}{l}\text { Males } \\
\text { Females }\end{array}$ & $\begin{array}{l}13.90 \\
15.70\end{array}$ & $\begin{array}{l}7.25 \\
1.24\end{array}$ & $\begin{array}{l}12.05 \\
12.98\end{array}$ & $\begin{array}{r}6.94 \\
.50\end{array}$ & $\begin{array}{l}10.70 \\
14.38\end{array}$ & $\begin{array}{r}6.09 \\
.62\end{array}$ \\
\hline
\end{tabular}

* Standard deviation of all transition values in each 30-trial staircase measurement. $\quad * *$ Total number of transition points in each 30-trial staircase measurement. mean of the three uncertainty ranges for the three series in the measurement).

A $2 \times 2 \times 3$ (sex $\times$ method $\times$ time) analysis of variance was calculated with uncertainty range as the dependent variable. The two levels of method consisted of the 1-series bracketing and the 3-series bracketing variations. The three levels of the time variable again represented the $3 \mathrm{~h}$ of measurement. For each subject, the mean range of uncertainty for a given method was calculated for each time period. The cell means and standard deviations are shown in Table 3. There was a significant sex difference $[F(1,8)$ $=5.43, \mathrm{p}<.05$ ], with females showing greater variability than males. There was a nearly-significant effect of time $[F(2,16)=3.21, p<.07]$ and a significant interaction between sex and time $[F(2,16)=3.61$, $p=.05]$. These last two findings resulted from the fact that females increased in variability with time, while males did not. There was no significant effect due to method, and none of the other interactions was significant.

\section{Amount of Time Required for. Different Methods}

A $2 \times 2 \times 3$ (sex $\times$ method $\times$ time) analysis of variance was calculated, with the amount of time required to make each dark-focus measurement as the dependent variable. The two levels of method were staircase and 3-series bracketing (no time records were kept for the 1-series bracketing measurements). The three levels of the time variable again represented the $3 \mathrm{~h}$ of measurement. For each subject, the mean amount of time (in minutes) required for each measurement for each technique was calculated for each hour. The means and standard deviations for this analysis are shown in Table 4. There was a significant effect due to method $[F(1,8)=6.10, p<$ $.04]$ - the staircase method required significantly more time than did the 3-series bracketing method. None of the other main effects was significant, nor were any of the interactions.

\section{0-Trial Staircase vs. 20-Trial Staircase}

Since the staircase method required somewhat more time to do than did the 3-series bracketing method, it seemed desirable to find some way to shorten it. One way would be to give only 20 trials rather than the 30 used in this study. All the staircase measures for all 10 subjects were rescored using only the first 20 trials of each measurement. For each subject, the 20-trial dark-focus values and the 30-trial dark-focus values were compared using Pearson product-moment correlation coefficients. The 10 resulting correlation coefficients had a mean value of $0.98(\mathrm{SD}=0.03)$. Then the mean of each subject's 20 trial staircase measures and the mean of his/her 30trial staircase measures were calculated. The correlation between these two values across all 10 subjects was examined, yielding a perfect 1.00 correlation co- 
Table 3

Variability Data for Bracketing Method

\begin{tabular}{|c|c|c|c|c|c|c|}
\hline \multirow[b]{3}{*}{ Sex } & \multicolumn{6}{|c|}{ Time of Measurement } \\
\hline & \multicolumn{2}{|c|}{ First Hour } & \multicolumn{2}{|c|}{ Second Hour } & \multicolumn{2}{|c|}{ Third Hour } \\
\hline & $\mathbf{M}$ & $\mathrm{SD}$ & M & SD & $\mathbf{M}$ & SD \\
\hline \multicolumn{7}{|c|}{ 1-Series Bracketing } \\
\hline $\begin{array}{l}\text { Males } \\
\text { Females }\end{array}$ & $\begin{array}{l}1.90 \\
2.37\end{array}$ & $\begin{array}{l}.74 \\
.84\end{array}$ & $\begin{array}{l}1.74 \\
4.02\end{array}$ & $\begin{array}{l}1.07 \\
3.99\end{array}$ & $\begin{array}{l}1.75 \\
4.87\end{array}$ & $\begin{array}{r}.71 \\
2.85\end{array}$ \\
\hline \multicolumn{7}{|c|}{ 3-Series Bracketing } \\
\hline $\begin{array}{l}\text { Males } \\
\text { Females }\end{array}$ & $\begin{array}{l}1.68 \\
2.68\end{array}$ & $\begin{array}{r}.72 \\
1.73\end{array}$ & $\begin{array}{l}1.86 \\
4.16\end{array}$ & $\begin{array}{r}.96 \\
1.68\end{array}$ & $\begin{array}{l}1.66 \\
5.05\end{array}$ & $\begin{array}{r}.97 \\
2.37\end{array}$ \\
\hline
\end{tabular}

Note-Values represented by means refer to range of uncertainty.

Table 4

Amount of Time Required for Each Psychophysical Method

\begin{tabular}{|c|c|c|c|c|c|c|}
\hline \multirow[b]{3}{*}{ Sex } & \multicolumn{6}{|c|}{ Time of Measurement } \\
\hline & \multicolumn{2}{|c|}{ First Hour } & \multicolumn{2}{|c|}{ Second Hour } & \multicolumn{2}{|c|}{ Third Hour } \\
\hline & $\mathbf{M}$ & SD & M & SD & $\mathbf{M}$ & SD \\
\hline \multicolumn{7}{|c|}{ Staircase } \\
\hline Males & 10.25 & 5.13 & 10.31 & 5.89 & 11.33 & 8.82 \\
\hline Females & 9.45 & 2.24 & 11.35 & 5.95 & 8.62 & 2.61 \\
\hline \multicolumn{7}{|c|}{ Bracketing } \\
\hline Males & 5.70 & 1.71 & 6.15 & 3.14 & 7.64 & 5.19 \\
\hline Females & 8.78 & 3.27 & 7.90 & 1.52 & 10.45 & 3.42 \\
\hline
\end{tabular}

Note-Means represent number of minutes required to make each measurement.

efficient. The overall mean for the 20-trial staircase data was $1.64 \mathrm{D}(\mathrm{SD}=\mathbf{0 . 8 0})$; for the 30 -trial staircase data it was $1.65 \mathrm{D}(\mathrm{SD}=0.80)$. Clearly, the two variations of the staircase method yielded nearly identical results.

\section{DISCUSSION}

\section{Dark-Focus Fatigue}

It is clear from the results of this study that a 3-h exposure to the visual task did not produce any significant changes in dark focus. There is no question that the task was a very demanding one. All subjects reported being extremely tired, with sore muscles and occasional headaches. Indeed, for some subjects, it was all they could do to finish the task. However, no demands were placed by the task on accommodation, and, as predicted, dark focus did not change. Such a finding complements the earlier-described work of Östberg and others suggesting that the dark-focus point represents "resting" accommodation. It is only when accommodative effort is required that fatigue effects can be observed.

Of course, the present study addresses only dark focus-it does not show what the effects of accommodation-free long-term visual work might be on accommodation to near or far targets. Such a question deserves further study. It also would be desirable to investigate the effects of far visual work on dark focus and accommodation to near and far targets. For that matter, more evidence regarding the effects of near work on these variables also is desirable, as Östberg and his colleagues reported results from only a relatively select task-the viewing of VDU terminals. It is possible, for example, that fatigue effects might be selective. That is, it is possible that near work might lead to a recession of the near point toward dark focus, but with no effect on the amplitude of accommodation beyond dark focus. However, the data that are available from this study and those of Östberg and his associates are consistent with the view that dark focus can be affected by longterm visual work only when actual accommodation effort is required. They also are consistent with the conception that the resting position of accommodation is not optical infinity, as was previously believed, but rather the dark-focus point.

Knowing that dark focus is immune to change, even in long-term tiring measurements, is useful for other research in dark focus. The experimenter who needs to make many such measurements need not fear that any resulting fatigue will have an impact on the dark-focus values themselves. Another practical implication is that placing visual displays at a distance commensurate with the user's dark focus may help eliminate problems of blurring often encountered with extended use. Certainly such an implication is worth an experimental test.

\section{Psychophysical Methods}

It would appear that all of the psychophysical variations used in this study yielded essentially the same results. If one is going to do research in which the important comparisons are between groups of subjects, any of these methods will serve well. For situations requiring rapid measurements, the 1-series bracketing method would appear to be the best. If there is more time for measurement, the staircase method provides the best psychophysics. If one is interested in the performance of individual subjects, the staircase method is probably best from a psychophysical standpoint, since it yields the greatest number of transition points. The only reason for preferring the 3-series bracketing method to the staircase method might be because the former is a bit faster, but even this advantage disappears if the staircase method is limited to 20 trials. An additional advantage of the staircase approach is that it can be used to approximate a continuous measure of accommodation. One can keep giving trials, without interruption, for as long as necessary; since each response transition represents an accommodation estimate, one can easily obtain several such estimates every minute. 


\section{Variability}

The variability data are difficult to interpret. One of the reasons for this is that it is not clear what the variability measures mean, from the subject's point of view. Probably all of the variability measures reflect, to some degree, the subject's confidence in his/her response. On the staircase measurements, for example, the unconfident subject probably would be reluctant to change responses unless he/she was sure of a change in the movement of the speckle pattern. Thus, the unconfident subject would show fewer response transitions than the confident subject. In a sense, this may reflect subject criterion, in much the same way as the term is used in signal detection theory. Fewer transitions per measurement would indicate a more conservative criterion; more transitions would indicate a more liberal criterion.

The results were not consistent, of course, but there was some tendency for variability to increase with time-in the above terms, subjects became more conservative with time. One can only speculate on the reasons for this. General exhaustion may have been one contributor. Adaptation of the red system, reducing contrast within the speckle pattern and thus reducing response certainty, may have been another. There also was some tendency for females to show more variability than males. Neither of these variability effects was really strong enough for serious theorizing, but they may be worth further investigation.

In summary, the present study showed that longterm accommodation-free visual work did not produce changes in dark focus. The study also explored the use of several psychophysical procedures in the assessment of accommodation, with the result that all the methods showed high agreement with one another. There were practical reasons for examining both of these things, as described above, and the absence of dark-focus fatigue effects is consistent with the dual-innervation theory of accommodation.

\section{REFERENCE NOTE}

1. Östberg, O., Powell, J., \& Blomkvist, A.-C. Laser optometry in assessment of visual fatigue (Tech. Rep. No. 1980:1 T). Lulea, Sweden: University of Lulea, Department of Human Work Sciences, 1980.

\section{RAFERENCES}

AlPERN, M. Accommodation. In H. Davson (Ed.), The eye (Vol. 3): Muscular mechanisms (2nd ed.). New York: Academic Press, 1969.

Berens, C., \& Selus, S. B. Experimental studies of fatigue of accommodation: I. Plan of research and observations of recession of near point of accommodation following a period of interpolated work on the ophthalmic ergograph. Archives of Ophthalmology, 1944, 31, 148-159.

Berens, C., \& SELls, S. B. Experimental studies of fatigue of accommodation. II. American Journal of Ophthalmology, $1950,33,47-58$.

Beren8, C., \& Stark, E. K. Studies in ocular fatigue: IV.
Fatigue of accommodation, experimental and clinical observations. American Journal of Ophthalmology, 1932, 15, 527-542.

Berger, C., \& Mahne ke, A. Fatigue in two simple visual tasks. American Journal of Psychology, 1954, 67, 509-512.

Brown, J. L. The structure of the visual system. In C. H. Graham (Ed.), Vision and visual perception. New York: Wiley, 1965.

Charman, $\mathbf{W}$. N. On the position of the plane of stationarity in laser refraction. American Journal of Optometry and Physiological Optics, 1974, 51, 832-838.

Cogan. D. G. Accommodation and the autonomic nervous system. Archives of Ophthalmology, 1937, 18, 729-766.

ConssweEt, T. N. The staircase-method in psychophysics. American Journal of Psychology, 1962, 75, 485-491.

Davson, H. The physiology of the eye (4th ed.). New York: Academic Press, 1980.

Dember, W. N., \& WARM, J. S. Psychology of perception (2nd ed.). New York: Holt, Rinehart \& Winston, 1979.

Dixon, W. J., \& Massey, F. J., Jn. Introduction to statistical analysis (2nd ed.). New York: McGraw-Hill, 1957.

Duke-Elder, S., \& Abrams, D. System of ophthalmology (Vol. 5): Ophthalmic optics and refraction. St. Louis: Mosby, 1970.

Ferree, C. E. Tests for the efficiency of the eye under different systems of illumination and a preliminary study of the causes of discomfort. Transactions of the Illuminating Engineering Society, 1913, 8, 40-60.

Ferree, C. E. The efficiency of the eye under different systems of lighting. Ophthalmology, 1914, 10, 622-636.

Fitzpatrick, J. P., \& Hansen, D. W. The relationship between classroom visual fatigue and academic achievement in elementary school children. Journal of the American Optometric Association, 1973, 44, 812-823.

Guilfond, J. P. Psychometric methods (2nd ed.). New York: McGraw-Hill, 1954.

Heaton, J. M. The pain in eyestrain. American Journal of Ophthalmology, 1966, 61, 104-112.

HenNessy, R. T., \& LEIBowitz, H. W. Subjective measurement of accommodation with laser light. Journal of the Optical Society of America, 1970,60, 1700-1701.

Hennessy, R. T., \& LeibowrTz, H. W. Laser optometer incorporating the Badal principle. Behavior Research Methods \& Instrumentation, 1972, 4, 237-239.

Howe, $L$. The fatigue of accommodation as registered by the ergograph. Journal of the American Medical Association, 1916, 67, 100-104.

INGELSTAM, E., \& RAgnargson, S.-I. Eye refraction examined by aid of speckle pattern produced by coherent light. Vision $R e$ search, 1972, 12, 411-420.

Kroll, H. A. Measuring ametropia with a gas laser: A preliminary report. American Journal of Optometry, 1966, 43, 415-418.

Lancaster, W. B., \& Williams, E. R. New light on the theory of accommodation with practical applications. Transactions of the American Academy of Ophthalmology and Oto-Laryngology, $1914,19,170$.

LE IBOWITZ, H. W. Visual perception and stress. In G. Borg (Ed.), Physical work and effort. New York: Pergamon, 1976.

Leibowitz, H. W., \& Hennessy, R. T. The laser optometer and some implications for behavioral research. American Psychologist, 1975, 30, 349-352.

LEIBowITZ, H. W., \& OWENB, D. A. Anomalous myopias and the intermediate dark focus of accommodation. Science, 1975, 189, 646-648.

Leibowitz, H. W., \& Owens, D. A. New evidence for the intermediate position of relaxed accommodation. Documenta Ophthalmologica, 1978, 46, 133-147.

Melton, C. E., Purnell, E. W., \& Brecher, G. A. The effect of sympathetic nerve impulses on the ciliary muscle. American Journal of Ophthalmology, 1955, 40, 155-162.

Mille R, R. J. Temporal stability of the dark focus of accommodation. American Journal of Optometry and Physiological Optics, 1978, 55, 447-450. (a) 
Miller, R. J. Mood changes and the dark focus of accommodation. Perception \& Psychophysics, 1978, 24, 437-443. (b)

Miller, R. J. Ocular vergence-induced accommodation and its relation to dark focus. Perception \& Psychophysics, 1980, 28, 125-132.

Miller, R. J., \& LeBeau, R. C. Induced stress, situationallyspecific trait anxiety, and dark focus. Psychophysiology, 1982, 19, 260-265.

Mohon, N., \& Rodemann, A. Laser speckle for determining ametropia and accommodation response of the eye. Applied Optics, 1973, 12, 783-787.

OGLE, K. N. Optics: An introduction for ophthalmologists (2nd ed.). Springfield, Ill: Thomas, 1968.

Östbera, O. Accommodation and visual fatigue. In E. Grandjean (Ed.), Ergonomics of VDU workplaces. London: Taylor \& Francis, 1980.

OWens, D. A., \& Leibowitz, H. W. The fixation point as a stimulus for accommodation. Vision Research, 1975, 15, 1161-1163.

Romaine, H. H., Fatigue of accommodation. The Eye, Ear, Nose and Throat Monthly, 1951, 30, 140-142.

Schober, $H$. On the resting position of accommodation (R. Koeck \& H. W. Leibowitz, Trans.). Optik, 1954, 11, 282-290.
Simmerman, H. Visual fatigue. American Journal of Optometry, $1950,27,554-561$.

TOATES, F. M. A model of accommodation. Vision Research, $1970,10,1069-1076$.

Toates, F. M. Accommodation function of the human eye. Physiological Reviews, 1972, 52, 828-863.

WEStON, H. W. Visual fatigue. Illuminating Engineering, 1954, 49, 63-76.

\section{NOTE}

1. The expression of dark focus in dioptric terms, as is the case whenever the amount of accommodation is being so expressed, assumes an eye with an infinity far point. Thus, any refractive errors must be taken into account, either through optical correction (as in the present study) or via a mathematical correction applying some variation of Donders' formula (see Duke-Elder \& Abrams, 1970).

(Manuscript received February 21, 1983; revision accepted for publication August 30, 1983.) 